\title{
GOVERNANÇA E CIDADANIA EMPRESARIAL
}

\author{
Lauro Eduardo Soutello Alves \\ Ex-Chefe do Setor de Ligação com a OCDE da Embaixada do Brasil em Paris. \\ E-mail: soutello@mre.gov.br
}

\begin{abstract}
RESUMO
O artigo procura traçar a evolução recente do conceito de cidadania empresarial e de sua principal manifestação: a evolução de padrões de comportamento empresarial socialmente responsável. Busca diferenciar a empresa oportunista e a empresa cidadã. Procura, ainda, inserir o conceito de comportamento socialmente responsável no contexto mais amplo da governança social, econômica e política. Além disso, sugere o possível caminho para uma investigação empírica capaz de determinar se a sustentabilidade das empresas ocorre em virtude de padrões de comportamento antes responsável do que oportunista. Retrata também a evolução recente de códigos de conduta empresarial em nível nacional e internacional. Termina com uma análise das possíveis implicações sociais e políticas da universalização da governança em geral e da

cidadania empresarial em particular, tanto para os países avançados quanto para os emergentes.
\end{abstract}

\section{ABSTRACT}

The article attempts to trace the recent development of the concept of good corporate citizenship and its impact on evolving standards of socially responsible corporate behavior. It seeks to differentiate opportunistic and responsible patterns of corporate behavior. It also attempts to place the issue of corporate social responsibility within the broader context of social, political and economic governance. Furthermore, it suggests future empirical work to determine if sustainable businesses are those that follow higher standards of corporate social responsibility. It discusses the recent growth of international corporate codes of conduct. It concludes by attempting to anticipate some of the social and political consequences of future universal governance regimes and codes of corporate conduct for both the advanced and emerging economies.

Governança, cidadania, comportamento, códigos, stakeholders.

Governance, corporate citizenship, behavior, codes, stakeholders. 


\section{INTRODUÇÃO}

A desconfiança, justificada ou não, de amplo segmento do público internacional com relação às empresas em geral e às multinacionais em particular tem figurado como um dos elementos da reação contrária à globalização, como atestam recentes manifestações, freqüentemente violentas, de Seattle a Gotemburgo. Esse fenômeno parece ter suas raízes não só na constatação do poder e da influência das grandes empresas multinacionais, altamente visíveis e presentes no mundo inteiro, mas também na tendência do público de personalizar as grandes empresas e de vê-las como indivíduos, capazes de bom ou de mau comportamento.

Segundo o autor socialista Arnold Thurman, essa personificação, entendida como fenômeno psicossocial, explicaria a tendência de se atribuir às empresas direitos e prerrogativas superiores aos normalmente atribuídos ao cidadão (parte do que o autor chamou de "feudalismo industrial"). A atual revolta contra a globalização em geral e as empresas multinacionais em particular poderia ser interpretada como uma reação contra o que se percebe como uma classe privilegiada, capaz de atuar livremente em escala mundial, freqüentemente com o beneplácito, senão o apoio, dos governos (Thurman, 1937).

Paralelamente, nos países mais avançados, a opinião pública tem passado a exigir de suas empresas a observância de padrões de comportamento socialmente responsável, tanto nas matrizes quanto nas filiais localizadas em países emergentes ou em desenvolvimento. A globalização teria acentuado essas preocupações, diante da possibilidade de que as empresas multinacionais procurem, cada vez mais, instalar-se em países que permitem a aplicação de padrões de comportamento inferiores ou inaceitáveis para a opinião pública nos países desenvolvidos.

A pressão pela adoção de padrões de comportamento socialmente responsável poderá contribuir para mitigar os eventuais efeitos negativos da globalização fenômeno cujo progresso não seria, como afirmam autores como Alain Touraine, impessoal e inexorável, senão o resultado de políticas concretas nos planos social e econômico (Touraine, 1999).

O presente artigo busca identificar a possível base teórica dos padrões emergentes de comportamento socialmente responsável, sobretudo nos países mais avançados. Pretende, ainda, inseri-los no contexto mais amplo da governança. Procura, por fim, avaliar as possíveis conseqüências da universalização desses padrões e suas implicações sociais e políticas.

TEORIA DA EMPRESA

E CIDADANIA EMPRESARIAL

O núcleo fundamental da economia de mercado sempre foi e continua a ser a empresa - entidade social, econômica e jurídica de natureza flexível e elástica, de vez que pode assumir diversas formas, conforme suas funções, suas dimensões e a composição de seu capital. Empresas podem ser pequenas, médias ou grandes; nacionais ou multinacionais; privadas, públicas ou de capital misto. A variedade é potencialmente infinita. Mesmo assim, a empresa mantém sua identidade e função como núcleo básico da economia.

\section{A NOVA CONCEPÇÃO DE EMPRESA SOCIAL GANHA NÚMERO DE}

\section{ADEPTOS CADA VEZ MAIOR, NÃO APENAS NOS PAÍSES \\ INDUSTRIALIZADOS MAS NOS PRINCIPAIS PAÍSES EMERGENTES.}

O objetivo primordial da empresa continua a ser o de produzir bens e de prestar serviços da forma economicamente mais eficiente. Quaisquer desvios desse objetivo básico, como ocorria no caso das empresas estatais das antigas economias socialistas - atualmente economias em transição - ou de algumas empresas estatais ou semi-estatais de países em desenvolvimento, levam à ineficiência e ao desperdício de recursos em detrimento do desempenho da empresa e da eficiência econômica.

Por outro lado, o crescimento e a diversificação das grandes empresas nos principais países industrializados revelam que o papel da empresa na sociedade não se restringe meramente à produção de bens ou à prestação de serviços em condições eficientes, assim como não se limita à maximização do lucro para os acionistas, porém consiste, antes, na geração de riqueza em um sentido mais amplo.

Essa riqueza traduz-se, entre outros, em termos de conhecimento, tecnologia, empregos, infra-estrutura energética e de comunicações. As economias externas criadas pelas grandes empresas, ademais, contribuem para o desenvolvimento sustentável, às vezes, independentemente dos objetivos imediatos da empresa e de seus métodos de gestão. Ao colaborar com o desenvolvimento, a empresa pode até contribuir para a estabilidade de um país ou de uma região, com implicações políticas e estratégicas.

O papel da empresa como principal geradora de riqueza suscita, portanto, a questão de saber se a empresa tem uma função social e se, nesse caso, é possível ou desejável estabelecer que tenha determinadas obrigações com a sociedade, além da geração de riqueza material. 
Há mais de meio século, John Maynard Keynes afirmou que o gradual crescimento da empresa tem como correlata a diversificação de suas funções. Segundo o eminente economista britânico, a maximização do lucro para os acionistas passa, à medida que a empresa cresce, a ocupar papel quase secundário. A estabilidade da empresa, sua imagem perante o público e sua capacidade de satisfazer os seus clientes passam a ocupar papel de destaque (Keynes, 1947). Keynes não chegou, contudo, a prever a atribuição de uma função social à empresa, e sua visão de "corporações imperiais", preocupadas com questões outras que as estritamente econômicas, não invalida a concepção da empresa como núcleo básico de geração de riqueza.

A concepção de uma empresa social, comprometida com objetivos outros que os de geração de riqueza material, ganhou corpo nas décadas de 60 e 70, promovida por correntes de pensamento e movimentos de protesto que propunham modelos críticos e alternativos ao capitalismo avançado e à sua instituição fundamental: a empresa.

Alguns autores liberais logo se ergueram em ferrenhos críticos da noção de empresa social, negando tanto a possibilidade prática quanto a utilidade de atribuir quaisquer funções sociais específicas às empresas.

Em célebre artigo publicado em 1974, o professor Milton Friedman, da University of Chicago, afirmou que a única responsabilidade social da empresa consiste em utilizar seus recursos para maximizar o lucro em benefício dos acionistas, mantendo-se fiel ao que caracterizou como as "regras do jogo", regras essas que se limitam a não fraudar os acionistas e credores e a respeitar as regras da concorrência leal ${ }^{1}$.

$\mathrm{O}$ economista e colega de universidade de Milton Friedman, Friedrich von Hayek, por sua vez, atacou o que caracterizou como a "doutrina da moda" (fashionable doctrine) de atribuir quaisquer funções às empresas além da maximização do lucro em longo prazo.

Levada às últimas consequiências, essa tendência teria como resultado o aumento do poder das empresas, com efeitos política e socialmente imprevisíveis e indesejáveis, sobretudo se as grandes empresas passassem a determinar as prioridades sociais, econômicas ou políticas da sociedade (Hayek, 1967).

As visões críticas de Friedman e Hayek tiveram como ponto de partida a rejeição de toda intromissão nas forças de mercado, característica da obra do economista norte-americano, e o temor de uma empresa corporativista e totalitária, típica do pensamento de seu colega austríaco naturalizado britânico.

Em obra recente, a autora norte-americana Margaret Blair (1998) abordou o problema por um viés antes pragmático do que ideológico, concluindo que o conceito de empresa social é essencialmente falho e que a empresa social, tal como preconizada nas dé- cadas de 60 e 70, não prosperou por não oferecer alternativa viável à empresa clássica.

Segundo Margaret Blair, a própria concepção de empresa social carece de sólido fundamento teórico, ao contrário da noção clássica da empresa como unidade fundamental da economia de mercado. A noção de empresa social não é, ademais, suficiente para orientar o investimento das empresas nem para ajudá-las a escolher entre formas alternativas de atividade social. Essa noção não é acompanhada, ainda, de mecanismos de imposição para garantir que as empresas cumpram suas obrigações sociais.

Blair poderia ter acrescentado que a noção de obrigação social implica a necessidade de determinar instâncias competentes para definirem essas obrigações, bem como quem seriam os beneficiários da ação social das empresas - tarefas complexas e difíceis.

Autores como Blair assinalam, por outro lado, que o crescimento e a diversificação das grandes empresas têm reforçado o conceito de empresa como principal fonte de riqueza para a sociedade, porém não apenas no sentido material.

Segundo essa concepção, a geração de riqueza pela empresa pode-se estender além da maximização do lucro, em benefício dos acionistas ou credores, da geração e manutenção de empregos e do desenvolvimento de infra-estrutura de pesquisa, desenvolvimento e comunicações. Ela passa a incorporar a preservação dos recursos naturais não renováveis, a promoção de direitos fundamentais do trabalhador e a proteção dos interesses do consumidor.

Essa concepção ampla de geração de riqueza não se fundamenta apenas no que as empresas devem fazer, mas também no que devem deixar de fazer (e que muitas vezes fazem): poluir o meio ambiente, empregar trabalho infantil, encobrir informações sobre possíveis efeitos nocivos de seus produtos, etc.

A nova concepção de empresa que surge no período recente tem pouca relação com a da empresa social de outra época. A empresa atual mantém seu caráter essencial de geradora de riqueza, sem a atribuição de funções sociais alheias ao seu funcionamento e aos seus métodos de gestão, porém passa a fazê-lo, idealmente, de forma socialmente responsável.

A própria definição de riqueza, por sua vez, é ampliada, passando a incorporar não somente bens materiais tangíveis mas também valores intangíveis (ou, como querem alguns, éticos) - como a preservação do meio ambiente, o desenvolvimento sustentável, a dignidade no trabalho e a defesa do consumidor.

Esses valores, de caráter universal, pressupõem a existência de partes direta ou indiretamente interessadas na criação de riqueza pela empresa e que não são coincidentes com as tradicionais partes interessadas (i.e., os acionistas e os credores). Essas partes interes- 
sadas (stakeholders, no jargão especializado) englobam sindicatos, entidades de classe, associações de consumidores, organizações não governamentais de toda natureza e até a comunidade local em que as empresas operam. Constituem grupo heterogêneo e difuso, ao contrário da empresa, que mantém identidade clara, mesmo se a sua estrutura for complexa e dispersa no tempo e no espaço.

O gradual reconhecimento desse papel constitui, do ponto de vista sociológico, um dos aspectos fundamentais da recente evolução da empresa e de seus métodos de gestão. Se a antiga noção de empresa social parece estar desacreditada, por carecer de embasamento conceitual e aceitação pela sociedade, a nova concepção, que se pode chamar de empresa cidadã, ganha número de adeptos cada vez maior, não apenas nos países industrializados mas nos principais países emergentes.

Para compreender melhor a concepção de cidadania empresarial, é necessário analisá-la à luz do fenômeno mais amplo conhecido como governança.

\section{GOVERNANÇA, GOVERNABILIDADE E O DILEMA DO PRISIONEIRO}

Cidadania empresarial, entendida como um conjunto de princípios e sistemas de gestão destinados à criação ou preservação de valor para a sociedade, pode ser englobada no conceito mais amplo de governança - o qual inclui o conceito de governança corporativa, mas não se restringe a ele.

Governança é um conceito freqüentemente difuso, podendo ser aplicado tanto a métodos de gestão da empresa (governança corporativa) quanto a meios de preservação do meio ambiente (governança ambiental) ou formas de combate ao suborno e à corrupção de funcionários públicos (governança pública). Não obstante seu caráter difuso, o conceito de governança tem como ponto de partida a busca do aperfeiçoamento do comportamento das pessoas e das instituições.

Tal conceito recorda a teoria da engenharia social paulatina (piecemeal social engineering), criada pelo filósofo Sir Karl Popper para descrever um processo aproximativo e constante de aperfeiçoamento da sociedade, ao contrário da engenharia social utópica, que pressupõe uma visão única e ideal de sociedade, cuja construção constitui o principal objetivo de toda atividade política, social e econômica - "the method of searching for, and fighting against, the greatest and most urgent evils of society, rather than searching for, and fighting for, its greatest ultimate good" (Popper, 1971).

A governança não se limita, portanto, a promover o funcionamento mais eficiente, no sentido superficial, das instituições: governança não é sinônimo de governabilidade (tampouco é sinônimo de filantropia ou as- sistencialismo).

Para exemplificar, tome-se o exemplo de duas empresas. É perfeitamente concebível que uma delas produza determinado produto de maneira eficiente empregando trabalho infantil. É igualmente concebível que a outra produza o mesmo produto de forma eficiente, sem empregar trabalho infantil, mas a um custo superior do que sua concorrente.

Segundo o critério puramente funcional, ambas as empresas estariam produzindo de forma eficiente, mas a primeira estaria em vantagem com relação à segunda em função de seus custos menores. Segundo o conceito de governança, ambas as empresas estariam produzindo de forma aparentemente eficiente, mas a primeira estaria em desvantagem com relação à segunda pelo fato de que o custo social decorrente do emprego de trabalho infantil termina por encarecer o seu produto e anular qualquer vantagem comparativa.

\section{O COMPORTAMENTO SOCIALMENTE} RESPONSÁVEL TERMINA POR SER MAIS SUSTENTÁVEL EM LONGO PRAZO DO QUE O COMPORTAMENTO

\section{MERAMENTE OPORTUNISTA.}

A primeira empresa age de forma oportunista, ao procurar maximizar o lucro em detrimento dos princípios de cidadania empresarial. Ela é cúmplice, em última análise, de um processo produtivo que subverte valores sociais essenciais para o desenvolvimento sustentado da sociedade e da economia em longo prazo.

A segunda empresa atua de forma socialmente responsável, em cumprimento aos princípios de cidadania empresarial. Ela participa, portanto, de um processo produtivo que termina por agregar valor social e, assim, contribuir para o desenvolvimento sustentado da sociedade e da economia em longo prazo.

Resta indagar se o comportamento da empresa oportunista é, como parece, insustentável em longo prazo, ao passo que o comportamento da empresa socialmente responsável não o seria.

Todo comportamento oportunista, ainda que eficiente em curto prazo, pressupõe a ausência de regras ou de formas eficazes de aplicá-las em detrimento dos princípios de governança. Todo comportamento socialmente responsável, por outro lado, tem por fundamento a confiança de que as regras serão fielmente cumpridas pela maioria de conformidade com os princípios de governança.

Em outras palavras, a empresa oportunista parte da suposição de que o seu interesse consiste em des- 
considerar as regras em vigor ou tirar proveito de suas lacunas, ignorando os princípios de governança, ao passo que a empresa socialmente responsável parte do pressuposto de que seu interesse consiste em cumprir e até superar as regras em vigor em prol dos princípios de governança.

\section{CONFORME PADRÕES DE}

\section{COMPORTAMENTO SOCIALMENTE}

RESPONSÁVEL DISSEMINAM-SE NOS

\section{PLANOS INTERNO E INTERNACIONAL,}

\section{OS STAKEHOLDERS E A SOCIEDADE}

\section{CIVIL ESPERAM QUE ESSES PADRÕES}

\section{SEJAM CODIFICADOS E IMPLEMENTADOS.}

A Teoria dos Jogos e, especificamente, o Dilema do Prisioneiro servem para ilustrar que o comportamento oportunista não seria, em última análise, sustentável, uma vez que o comportamento socialmente responsável (e, portanto, solidário) teria melhores possibilidades de sê-lo.

$\mathrm{O}$ dilema pode-se resumir da seguinte forma: dois prisioneiros, acusados de crimes análogos, são informados pelo promotor público de que, se nenhum dos dois confessar o crime, ambos serão condenados e receberão a pena mínima de um ano, ao passo que, se apenas um confessar, ele será libertado e o outro será condenado, recebendo a pena máxima de dez anos de reclusão. Se os dois confessarem, contudo, ambos serão condenados e receberão pena de apenas cinco anos de prisão.

Conforme assinalado pelo filósofo norte-americano John Rawls, o Dilema do Prisioneiro é um jogo em que os resultados não se cancelam mutuamente: o que um dos dois prisioneiros tem a perder, o outro não tem necessariamente a ganhar (a two-person, noncooperative, nonzero-sum game). Todo comportamento oportunista prejudica os dois. A única decisão mutuamente vantajosa é a de que um coopere com o outro, isto é, que ambos se recusem a confessar. Se um pudesse confiar na decisão do outro, com base num código comum, é provável que decidissem pela cooperação. Na ausência de um código, entretanto, é difícil que um confie no outro, sobretudo porque nenhum dos dois sabe ao certo se o promotor prometeu as mesmas condições a ambos (Rawls, 1971).

Essa abordagem sugere que o comportamento socialmente responsável - portanto coerente com os princípios de governança - termina por ser mais sustentável em longo prazo do que o comportamento meramente oportunista. A sustentabilidade do comportamento socialmente responsável, por sua vez, está fundamentada em códigos de conduta universal ou, na pior das hipóteses, apoiada por uma maioria significativa. Resta saber se a elaboração de tais códigos é uma proposição viável.

\section{O PROCESSO DE CODIFICAÇÃO}

A adesão ou o apoio generalizados a códigos de conduta socialmente responsável são elementos essenciais para que se estabeleça e se mantenha o clima de confiança necessário para que a empresa perceba que seu interesse reside antes em seguir padrões de comportamento responsável do que em agir de forma oportunista.

Os códigos em questão podem estar ou não previstos em lei, e a adesão a eles não deve ser confundida com o cumprimento formal de leis e regulamentos. O cumprimento da lei pode ser apenas perfunctório e não garantir a adesão a padrões de comportamento responsável. Pode, ainda, ser contornado sem incorrer na ilegalidade. É o caso de algumas empresas multinacionais, que burlam a lei ao deslocar suas operações para outros países (a lei pode ser obrigatória no país de origem da empresa, facultativa em outro e inexistente em um terceiro).

Ocioso recordar que o comportamento oportunista não implica necessariamente descumprimento da lei, mas antes o aproveitamento de suas lacunas. $\mathrm{O}$ comportamento responsável, por outro lado, acarreta aplicar padrões de conduta responsável, mesmo na ausência de leis e regulamentos específicos a respeito.

O clima de confiança mútua, por sua vez, tem como fundamento a certeza de que os códigos são claros e não discriminatórios, de que todas as empresas estão cumprindo os códigos (o princípio do level playing field) e de que o cumprimento é passível de verificação.

As empresas têm de ter certeza, ainda, de que eventuais violações estão sujeitas a sanção moral, penal ou econômica (i.e., a perda de mercado ou de uma fatia de mercado) e de que nenhuma empresa está se beneficiando de falhas no sistema para não cumprir os códigos.

O primeiro nível de verificação competiria às próprias empresas. Códigos de conduta individuais têm proliferado nos últimos anos, como atesta recente estudo da Organização para a Cooperação e o Desenvolvimento Econômico, em que se comparam centenas de códigos de conduta, na maior parte, códigos internos elaborados por empresas multinacionais (OECD, 2001).

Códigos individuais têm duas vantagens principais: refletem o cotidiano da empresa e são suficientemente flexíveis para se adaptarem a novas circunstâncias. Apresentam, por outro lado, as desvantagens de serem, freqüentemente, circunscritos a apenas algumas das atividades da empresa, sem levar em conta todos 
os aspectos das relações entre a empresa e o conjunto de stakeholders, e de não estarem sujeitos à verificação externa.

Códigos de conduta podem, também, ser comuns a toda uma indústria ou a todas as empresas de um país. A aplicação de um código de conduta em escala setorial ou nacional tem a vantagem de permitir algum grau de verificação mútua ou peer pressure, mas não abrange as atividades das empresas transnacionais.

Códigos de conduta universais, por sua vez, são os mais abrangentes, mas encontram-se ainda em estágio embrionário. Algumas iniciativas pioneiras apontam para a adoção crescente de tais códigos: as Diretrizes da OCDE para as Empresas Multinacionais, o Global Compact das Nações Unidas e os diversos códigos adotados pela Câmara de Comércio Internacional.

As Diretrizes (Guidelines) da OCDE foram adotadas em junho de 1999 pelos países membros da Organização, com a adesão de três países não membros: Argentina, Brasil e Chile. Na realidade, trata-se da revisão das guidelines de 1976, elaboradas pela OCDE em resposta à tentativa de criação, no âmbito das Nações Unidas, de um código de conduta mandatório para as empresas multinacionais.

O código da ONU - que fora motivado, entre outros fatores, pelas alegações de envolvimento da multinacional norte-americana de telecomunicações ITT no golpe de Estado de 1974 contra o Presidente Salvador Allende, do Chile - jamais foi finalizado, dada a resistência dos países desenvolvidos em aceitar que os países em desenvolvimento, majoritários na Organização, impusessem padrões obrigatórios de comportamento às empresas multinacionais ${ }^{2}$.

As Diretrizes da OCDE seriam, nesse particular, de especial relevância. Trata-se de um conjunto de princípios elaborado por organismo internacional, dedicado à cooperação econômica e social e à elaboração de princípios de governança nas mais diversas áreas, que reúne a quase-totalidade dos países industrializados e alguns grandes países emergentes, em que estão domiciliadas as principais empresas multinacionais.

São os seguintes os países membros da OCDE: Alemanha, Austrália, Áustria, Bélgica, Canadá, Coréia, Dinamarca, Espanha, Estados Unidos, Finlândia, França, Grécia, Hungria, Irlanda, Islândia, Itália, Japão, Luxemburgo, México, Nova Zelândia, Noruega, Países Baixos, Polônia, Portugal, Reino Unido, República Eslovaca, República Tcheca, Suécia, Suíça e Turquia. O Brasil participou da negociação das Diretrizes, embora não seja formalmente um país membro da OCDE.

Esses códigos têm várias vantagens sobre os demais: são de aplicação universal ou quase universal, cobrem a maioria ou a totalidade das atividades das empresas e representam correntes de pensamento avançadas sobre comportamento empresarial socialmente responsável; são voluntários e não vinculatórios, o que estimula a adesão espontânea das empresas e facilita o processo de revisão periódica dos códigos; prevêem o envolvimento dos governos ou federações industriais e comerciais, que são incentivados a zelar para que suas empresas sigam os princípios e padrões neles refletidos.

Tais códigos têm a desvantagem, contudo, de serem

\section{EXISTE EVIDÊNCIA DE UM PROCESSO}

\section{DE CONVERGÊNCIA ENTRE GOVERNABILIDADE E GOVERNANÇA:}

\section{EM OUTRAS PALAVRAS, A PRIMEIRA NÃO EXISTIRIA SEM A SEGUNDA.}

pouco sujeitos a verificação, de não preverem sanção (a não ser sanção moral) e de serem necessariamente genéricos. Apresentam a desvantagem, ainda, de não se estenderem a todos os fornecedores das empresas ao longo da cadeia produtiva, o que pode gerar problemas para empresas multinacionais (e.g., uma empresa de vestuário que produz seus produtos de forma socialmente responsável, mas que utiliza tecidos produzidos em fábricas que empregam trabalho infantil).

O fato de que os códigos internacionais existentes são voluntários não significa, no entanto, que sejam necessariamente opcionais. À medida que padrões de comportamento socialmente responsável disseminamse nos planos interno e internacional, cresce a expectativa dos stakeholders e da sociedade civil em geral de que esses padrões sejam codificados e implementados.

A sociedade civil pode pressionar política e economicamente para que as empresas cumpram esses códigos, sobretudo se forem domiciliadas em países cujos governos tenham se associado a eles. Como consequiência, as empresas que não se comportarem de forma socialmente responsável podem encontrar-se em desvantagem comparativa com relação àquelas que seguem códigos de conduta.

Resta a indagação sobre a existência de dados empíricos que consubstanciem essas hipóteses.

\section{CIDADANIA EMPRESARIAL: REALIDADE OU MITO?}

Há indícios de que o número de fatores que influem na capacidade de as empresas competirem no mercado global tende a incluir a adesão a padrões de comportamento socialmente responsável.

Segundo autores como Charles Oman, esses fato- 
res incluem não apenas políticas de concorrência, regulamento dos mercados financeiros e normas de produção, mas também padrões trabalhistas, normas de defesa do consumidor, padrões de proteção ambiental, normas de licitação pública e subsídios governamentais à pesquisa científica e tecnológica, entre outros (Oman, 1999).

Esse fenômeno contrasta com a imagem, amplamente difundida entre críticos da globalização, da empresa multinacional oportunista, que se desloca da matriz para países em que os padrões de responsabilidade social são mais baixos, incitando suas concorrentes a fazê-lo e declanchando, assim, o rebaixamento de padrões de conduta em escala global (a chamada race to the bottom) ${ }^{3}$.

Outros autores afirmam que empresas socialmente responsáveis seriam mais rentáveis em longo prazo do que empresas caracterizadas por um comportamento puramente oportunista, na medida em que estariam em melhores condições de conciliar, da forma mais eficiente e objetiva, os interesses de seus stakeholders "the socially responsible firm is better able than its opportunistic rivals to solve commitment problems that might arise with employees, with customers and with other firms" (Frank, 1996).

Essa análise pressupõe a existência de diversos stakeholders, todos com capacidade de influir nos processos decisórios da empresa, o que ocorre raramente. Presume, igualmente, que o comportamento desses stakeholders seria invariavelmente racional, o que pode não ser o caso. Considera, ainda, que a empresa seria capaz de lidar eficazmente com todos os stakeholders e de conciliar seus interesses, por vezes conflitantes tarefa em si difícil.

Existe, por outro lado, alguma evidência de que privatização de empresas estatais, sobretudo em países em desenvolvimento, contribui para elevar as expectativas dos consumidores de seus produtos ou dos usuários de seus serviços, que passam a pressionar as empresas privatizadas a adotarem padrões mais elevados de comportamento social.

A privatização de empresas fornecedoras de serviços vitais nas áreas de saúde, transportes ou telecomunicações, por exemplo, tende a gerar expectativas maiores por parte dos usuários em muitos países, anteriormente acostumados a níveis medíocres de atendimento ou serviço e que passam a exigir níveis mais elevados.

A privatização dessas empresas tem obrigado os novos prestadores de serviços públicos a se comprometerem com o cumprimento de normas mais estritas do que as normalmente aplicáveis à prestação de serviços privados. Tem, igualmente, exigido dos governos que zelem pela qualidade dos serviços prestados, mediante a elaboração de quadro regulatório (regulatory framework) adequado.

É lícito afirmar que existe evidência de um proces- so de convergência entre governabilidade e governança: em outras palavras, a primeira não existiria sem a segunda. Tal evidência é, no entanto, de natureza mais circunstancial do que propriamente empírica e requer trabalho de pesquisa que ultrapassa o escopo do presente artigo.

\section{A UNIVERSALIZAÇÃO DE PADRÕES DE CONDUTA}

Códigos internacionais de comportamento empresarial, ainda que voluntários, exigem a participação de governos nacionais, detentores da necessária legitimidade política para assumir compromissos internacionais em nome de empresas domiciliadas em seu território.

Códigos dessa natureza, por sua vez, requerem transparência e verificação mútua entre os países envolvidos. Conforme assinalado por autores como $\mathrm{Pa}-$ tricia Hansen, o cerne de qualquer sistema de verificação consiste no acesso mútuo e transparente à informação. Esse acesso, por sua vez, serve como elemento de dissuasão contra eventuais violações, tranqüiliza as partes interessadas de que todos estão cumprindo as mesmas regras, sem se aproveitar de eventuais lacunas, e permite iniciativas de verificação mútua, de modo a evitar conflitos - em outras palavras, a antítese do Dilema do Prisioneiro (Hansen, 1999).

O processo de difusão de padrões de conduta socialmente responsável parece estar apenas começando, não havendo, a priori, elementos para crer que ele não possa estender-se indefinidamente, sem horizonte claro no espaço ou no tempo.

Esse processo tem sido impulsionado pelo próprio fenômeno da globalização, que tende a reforçar tendências à padronização de métodos de produção, à uniformização da prestação de serviços e à universalização das inovações tecnológicas.

Esse processo não se limitaria, ainda, apenas à difusão entre número crescente de empresas, em cada vez mais países, de padrões de comportamento avançados, porém estenderia-se ao aperfeiçoamento desses padrões, que seriam cada vez mais elaborados, terminando por abarcar todos os aspectos da atividade das empresas.

Uma comparação entre as Diretrizes da OCDE para as Empresas Multinacionais adotadas em 1976 - e sua versão revista finalizada em 1999 - indica claramente que, em pouco menos de um quarto de século, a concepção de responsabilidade social das empresas cresceu de forma notável, passando a incluir compromissos claros em matéria de proteção ambiental, normas trabalhistas e proteção do consumidor, essencialmente ausentes no primeiro texto ${ }^{4}$. 


\section{IMPLICAÇÕES SOCIAIS E POLIITICAS}

O processo de aprofundamento indefinido do conceito de governança em geral e de responsabilidade social das empresas em particular teria implicações potencialmente negativas para as empresas, sobretudo se viesse a introduzir certa rigidez no planejamento e gestão de suas atividades (e.g., a exigência de que a transparência - princípio basilar da governança e da responsabilidade social das empresas - fosse total, aplicandose ao processo decisório interno em todos os seus aspectos, sem qualquer salvaguarda de confidencialidade).

Existem, no momento, várias correntes de pensamento sobre a questão. Segundo alguns autores, a questão da perda de autonomia individual é essencialmente neutra, sendo corolário inevitável da politização da esfera privada - "politicization exposes the arbitrariness or conventionalism of traditional definitions of "the private"” (Keane, 1998). Essa politização, por sua vez, é fruto do próprio processo democrático e do crescimento exponencial dos meios de comunicação tradicionais - imprensa escrita e televisiva - e contemporâneos - Internet (Keane, 1998).

Outros vêem na perda da autonomia individual um aspecto nocivo do desenvolvimento tecnológico e das técnicas de gestão das próprias empresas ("in the virtual office, privacy may be virtually lost"(Bies, 1996)), que se mostram cada vez mais totalitárias - "the core assumptions of modern management theory are totalitarian" (Bies, 1996).

Ainda outros consideram que a liberdade absoluta e, por conseguinte, a autonomia e privacidade absolutas são inviáveis na prática e terminam por serem nocivas, se não forem temperadas e limitadas pela ética - "our freedoms may mean nothing if not limited by moral rules" (Tyler, 2000).

$\mathrm{O}$ aprofundamento da governança poderia, ademais, terminar reforçando tendências autoritárias não somente na gestão da empresa mas também de toda a sociedade, na medida em que a extensão sem limite de regras, padrões e princípios de comportamento deixaria cada vez menos margem de iniciativa para as empresas e os indivíduos - com conseqüências políticas, sociais e econômicas possivelmente nefastas.

Alguns autores, dentre os quais o eminente sociólogo britânico Ralf Dahrendorf, têm advertido contra concepções autoritárias de governança, sobretudo no plano internacional, diante do que caracterizam como a acomodação e a apatia do grande público, que estariam permitindo que tais concepções se consolidassem - "today, the temptations of leadership and the comforts of public apathy can combine to form a perilous attack on liberty" (Dahrendorf, 2000). Sua visão recorda, grosso modo, a de Friedrich von Hayek, anteriormente citada.
Por outro lado, Dahrendorf estaria talvez subestimando os mecanismos de controle democráticos de que dispõem os países mais avançados para impedir que tal fenômeno se concretize.

A universalização dos princípios de governança em geral e do comportamento empresarial responsável em particular teria, como conseqüência prática, o virtual desaparecimento de políticas econômicas e sociais realmente autônomas. A definição dessas políticas estaria a cargo de uma constelação de stakeholders os mais diversos: setor público, setor privado, sindicatos, organizações não governamentais e organismos internacionais de vocação normativa ou reguladora.

\section{A UNIVERSALIZAÇÃO DOS PRINCÍPIOS DE} GOVERNANÇA E DO COMPORTAMENTO EMPRESARIAL RESPONSÁVEL TERIA, COMO CONSEQÜÊNCIA PRÁTICA,

O VIRTUAL DESAPARECIMENTO DE POLIITICAS ECONÔMICAS E SOCIAIS

\section{REALMENTE AUTÔNOMAS.}

Esses padrões flexíveis de autoridade traduziriamse na necessidade de elaboração de uma cultura empresarial - e de sistemas de gestão correspondentes - capaz de lidar com um ambiente social e econômico e com processos decisórios potencialmente muito mais complexos do que os atuais.

Levada ao extremo, a proliferação de entidades responsáveis pela elaboração de padrões de comportamento responsável - no âmbito dos setores público e privado - poderia terminar transformando o atual sistema internacional - baseado em estados politicamente soberanos e economicamente interdependentes - no que o cientista político Hedley Bull caracterizou como um sistema fluido de vários níveis de autoridade e lealdade "a system of overlapping authority and multiple loyalties" (Bull, 1977).

Ocioso recordar que essa perspectiva apresentaria grande atrativo para alguns e possível ameaça para outros.

\section{CONCLUSÃO}

A evolução da governança em geral e da cidadania empresarial em particular está sujeita a uma série de imponderáveis: a superação de padrões de comporta- 
mento oportunista por padrões de comportamento responsável; a adoção de códigos consensuais de cidadania empresarial e de mecanismos confiáveis de verificação; o desenvolvimento de métodos de gestão capazes de conciliar os anseios diversos, e porventura conflitantes, da sociedade civil; a manutenção de um equilíbrio entre, por um lado, a livre iniciativa e, por outro, os imperativos da cidadania empresarial.

Se a governança e a cidadania empresarial evoluírem positivamente, é lícito vislumbrar um futuro em que as empresas estejam em melhores condições do que nunca para realizar sua função principal: a de gerar riqueza e valor para a sociedade em uma base sustentável.

A hipótese de um futuro de prosperidade sustentada e sustentável teria como corolário a progressiva redução do desnível entre os países mais altamente industrializados e o grupo de países ditos emergentes (atualmente mais numerosos do que há poucas décadas).

Conforme comentário de alto funcionário da OCDE, em conversa recente com este, o mundo não será, futuramente, dividido entre ricos e pobres, mas entre reformadores e não reformadores, entre os que aceitam a governança e a cidadania como fundamentos de todo desenvolvimento sustentável e os que insistem em explorar fórmulas autônomas, que poderão revelar-se insustentáveis em longo prazo.

A inferência é de que todo desenvolvimento seja predicado em processo de reformas nos planos político, social, econômico e regulatório, mais do que em fatores históricos ou na disponibilidade de recursos naturais.

Esse processo pressupõe, naturalmente, que os países emergentes e em desenvolvimento, dentre os quais o Brasil, acompanhem o ritmo de reformas dos países desenvolvidos e que a adoção de padrões de governança e cidadania empresarial nos países menos avançados leve em conta suas inevitáveis deficiências institucionais e a consequiente dificuldade de assimilar padrões de conduta mais elevados. Seja qual for o seu nível de desenvolvimento, todo país terá, mais cedo ou mais tarde, de enfrentar o desafio de adequar-se a esses padrões ou, idealmente, de contribuir para a sua elaboração e seu aperfeiçoamento. $\bigcirc$

\section{NOTAS}

1. Citado em MESSNICK, David M., TENBRUSSEL, Ann E. (Eds.). Codes of conduct: behavioral research into business ethics. New York : Russel Sage Foundation, 1996. p. 86.

2. Para uma análise do código das Nações Unidas para as empresas multinacionais, ver FATOUROS, A. A. The UN Code of Conduct on transnational corporations: problems of interpretation and implementation e, para uma análise das guidelines da OCDE, ver LÉVY, Philippe. The OECD Declaration on International Investment and Multinational Enterprises, ambos em RUBIN, Seymour J., HUFBAUER, Gary Clyde. Emerging Standards of International Trade and Investment: Multinational Codes and Corporate Conduct, p. 101 a 118 e 47 a 62, respectivamente. Para uma discussão do papel da ITT no golpe que derrubou - Presidente Salvador Allende, ver MITCHELL, Christopher. Dominance and fragmentation in U.S. Latin American policy. In: COTLER, Julio, FAGEN, Richard R. Latin America and the United States: The Changing Political Realities, p. 194-197.
3. DONAHUE, J. Subnational Business-Attraction Policies in the United States, novembro de 1997, mimeografado, contribuição ao projeto de pesquisa do Centro de Desenvolvimento da OCDE, intitulado Effects of Competition among Governments to Attract fDI.

4. Ambos os textos estão disponíveis, em francês e em inglês, no site da OCDE na Internet: www.oecd.org.

\section{REFERÊNCIAS BIBLIOGRÁFICAS}

BIES, Robert J. Beyond the hidden self: aspects of privacy in organizations. In: MESSNICK, David M., TENBRUSSEL, Ann E. (Eds.). Codes of conduct: behavioral research into business ethics. New York : Russel Sage Foundation, 1996. p. 115.

BLAIR, Margaret M. The corporation and its stakeholders: classic and contemporary readings. Toronto : University of Toronto Press, 1998. Whose interests should corporations serve? p. 47.

BULL, Hedley. The anarchical society. London \& Basingstoke: Macmillan, 1977. p. 254-255.

DAHRENDORF, Ralf. The third way and liberty. Foreign affairs, p. 16-17, Sep./Oct. 2000.

FRANK, Robert H. Can socially responsible firms survive in a competitive environment? In: MESSNICK, David M., TENBRUSSEL, Ann E. (Eds.). Codes of conduct: behavioral research into business ethics. New York : Russel Sage Foundation, 1996. p. 86-103.
HANSEN, Patricia Isela. Transparency, standards of review, and the use of trade measures to protect the global environment. Virginia Journal of International Law, v. 39, n. 4, p. 1061, Summer 1999.

HAYEK, F. A. Studies in philosophy, politics and economics. London: Routledge \& Kegan Paul., 1967. p. 300 .

KEANE, John. Civil society: old images, new visions. Stanford : Stanford University Press, 1998. p. 183.

KEYNES, John Maynard. The end of laissez-faire. In: GOULD, James A., TRUITT, Willis H. Political ideologies. New York : Macmillan, 1973. p. 97.

OECD. Private initiatives for corporate responsibility: draft report to ministers By CIME. Paris : OECD, 2001.
OMAN, Charles. Globalization, regionalization, and inequality. Paris : OECD, 1999. (Development Centre Reprint Series, n. 93, p. 29)

POPPER, Karl R. The open society and its enemies. Princeton: Princeton University Press, 1971. V. I: The Spell of Plato. p. 158-159.

RAWLS, John. A theory of justice. Cambridge Belknap Press of Harvard, 1971. p. 269.

TOURAINE, Alain. Comment sortir du libéralisme? Paris : Librairie Arthème Fayard, 1999. p. 14.

THURMAN, Arnold. The folklore of capitalism. New Haven/London : Yale University Press, 1937. p. 185.

TYLER, Christian. The age of moral confusion. Financial Times, London, 22 Apr. 2000. 